\title{
Imperfeição calculada: [Rec] como paradigma do sound design em falsos documentários de horror
}

\section{Rodrigo Carreiro}

\section{Resumo}

Falsos documentários codificados como found

footage vêm se consolidando como um subgênero prolífico do cinema de horror. Na área do sound design, esse estilo de filme empurra os limites criativos em direção a uma estética que valoriza certo grau de imperfeição técnica. Como estudo de caso, propomos analisar o sound design de [Rec], filme de Paco Plaza e Jaume Balagueró, a fim de examinar como a construção sonora desse filme resolve 0 equilíbrio entre legibilidade e verossimilhança.

\section{Palavras-Chave}

Cinema de horror. Estudos do som. Sound design. Found footage. Zumbi.
Rodrigo Carreiro | rcarreiro@gmail.com Doutor em Comunicação pela Universidade Federal de Pernambuco (UFPE). Professor do Programa de Pós-Graduação em Comunicação da UFPE

\section{Introdução}

Há pelo menos duas décadas, a quantidade de filmes de horror estilisticamente construídos como documentários vem crescendo de modo exponencial. Desde a boa recepção de crítica e público ao filme estadunidense $A$ Bruxa de Blair (The Blair Witch Project, Eduardo Sánchez e Daniel Myrick, 1999), ${ }^{1}$ o número de realizações dentro do estilo tem aumentado sem parar, a ponto de parte da crítica cinematográfica dos Estados Unidos ter passado a tratar essa produção abundante como um gênero fílmico autônomo, intitulado por aficionados como found footage. ${ }^{2}$ Mas quais são as características em comum que esse grupo de filmes compartilha?

De modo geral, falsos documentários de horror construídos no estilo found footage $e^{2}$ constituem trabalhos audiovisuais de ficção que utilizam técnicas e recursos de estilo associados frequentemente ao modo de representação 
documental (NICHOLS, 2005, p. 135). Esses

filmes, contudo, narram enredos ficcionais.

As obras vinculadas ao ciclo de produção

emprestam elementos de estilo que geram uma

aparência naturalista - um tipo de efeito de real

(BARTHES, 1984, p. 43) - e podem confundir a

fruição do espectador sobre as características

ontológicas do universo ficcional.

A estratégia básica de construção estilística dos

filmes de found footage ficcionais, portanto,

consiste em estabelecer uma relação mimética

com as convenções de estilo do tipo de filme

comumente conhecido como documentário - ou,

em muitos casos, com a matéria-prima bruta

que serve de base ao documentário: registros

históricos do mundo real. É precisamente nesta

mimese do gênero documental que se estabelece

o jogo realista evocado pelos filmes de falso

found footage.

Este conjunto de filmes é constituído, dessa

forma, por obras de ficção construídas -

parcial ou totalmente - a partir de falsos

registros casuais (muitas vezes amadores ou

semiprofissionais) de situações extraordinárias

que se apresentam diante do aparato de

registro de imagens e sons. Para estabelecer

apropriadamente 0 jogo mimético com a estilística do documentário, os diretores

desses filmes precisam se certificar que

certas ferramentas de estilo e narrativa, que

identifiquem aos olhos do público aquelas

imagens e sons como tendo origem casual, sejam

devidamente percebidas pelo público como tal.

Daí a profusão de imagens escuras, imagens

captadas com câmera tremida, imagens sem foco, com a ação ocorrendo fora do campo de visão, com movimentos bruscos de câmera etc.

As imagens que compõem falsos documentários de horror são cuidadosamente construídas pelos diretores desses filmes para simular características normalmente encontradas em trabalhos amadores, semiprofissionais ou espontâneos. Em geral, a maior parte dos roteiristas e diretores desses filmes se esmera em criar situações ficcionais que permitam ao espectador indexar essas imagens como o resultado de uma estratégia de captação regida pelo acaso: um ou mais personagens fictícios agem como testemunhas de um fato extraordinário, e usam equipamentos de filmagem para registrar esse fato.

No campo da teoria do cinema, os filmes de found footage têm sido objeto de atenção de muitos pesquisadores (BRAGANÇA, 2011;

Alguns pesquisadores preferem usar outros termos, tais como: Point of View (POV) films ou discovered footage films (expressão lançada por David Bordwell). 0 principal objetivo seria evitar confusões com outro gênero fílmico, mais antigo e também chamado de found footage, que consiste em sua maioria da produção de documentários experimentais a partir da colagem e da ressignificação de imagens de arquivo pré-existentes. Cineastas como Péter Forgács, Harun Farocki e Martin Arnold são expoentes desse filão. Além disso, o termo found footage é impreciso para caracterizar os filmes a que este ensaio se refere, já que o suposto material encontrado consiste, na verdade, de imagens e sons ficcionais, fabricados com a intenção de parecerem registros casuais. 
BORDWELL, 2012; CÁNEPA, FERRARAZ, 2013;

GRANT, 2013; HELLER-NICHOLAS, 2011;

INGLE 2011), mas são poucos os estudos que examinam a construção formal desses trabalhos, procurando analisar e compreender a fundo os procedimentos estilísticos usados pelos cineastas para diferenciar esses filmes dos títulos de ficção tradicional. Do ponto de vista estilístico, pouco se tem discutido acerca dos filmes de found footage, embora eles tenham provocado mudanças até mesmo na poética do cinema mais convencional, como pode ser facilmente percebido quando verificamos, atualmente, a alta frequência com que a câmera operada manualmente - para citar apenas um exemplo - vem sendo utilizada em produções de poética mais convencional, que empregam a figura do narrador invisível e onisciente, posicionado em lugar privilegiado da diegese para continuar a prover o público de informações constantes sobre a progressão do enredo.

Quando se fala sobre elementos de estilo relacionados ao falso documentário construído como found footage, se costuma dar atenção à imagem. 0 som é muitas vezes negligenciado ou desprezado no estudo desse tipo de filme. Porém, praticamente todos os profissionais que trabalham na cadeia da produção do som em falsos documentários de found footage precisam executar seus respectivos trabalhos de modo peculiar. Isso ocorre porque esses profissionais têm que lidar, de forma que diverge do convencional, com uma disputa entre dois princípios da estilística cinematográfica que costumam ser conflitantes: a legibilidade narrativa e a verossimilhança documental (RUOFF, 1992, p. 207).

0 conflito entre esses dois princípios atravessa todo tipo de filme - e não apenas na área do som. Ele se manifesta do seguinte modo: os profissionais que trabalham na produção e na pós-produção de qualquer filme precisam se esforçar para representar com algum grau de realismo 0 universo diegético, mas também precisam se fazer entender com clareza e rapidez. É preciso conjugar os dois princípios. Nos filmes de falso found footage, a ênfase que se atribui a cada um dos dois princípios costuma ser bem diferente daquela vista em filmes de ficção tradicionais.

De modo geral, é possível afirmar que a legibilidade costuma levar vantagem nesse conflito, e não apenas na área do som. Afinal, o público precisa compreender as informações narrativas, relativas ao enredo, nos sons e imagens, para seguir a história que está sendo contada. Se for preciso sacrificar um pouco do realismo para que a narrativa seja claramente compreendida pelo público, a maior parte dos cineastas aceitará o sacrifício. Um exemplo: uma cena de refeição, dentro de filme de ficção, não costuma durar mais do que três ou quatro minutos, embora todos saibamos que o tempo necessário para executar a mesma ação, do lado de cá da tela, é muito maior. A elipse constitui 
uma das técnicas narrativas disponíveis aos cineastas para ampliar a legibilidade sem violar radicalmente a verossimilhança.

No que diz respeito ao som, o grau de excelência técnica alcançado pela tecnologia contemporânea de captação, edição e reprodução garante que o público seja capaz de ouvir com clareza, e de qualquer ponto da sala de exibição, qualquer som individual desejado pelo diretor ou pelo sound designer do filme. No caso dos falsos documentários de horror, contudo, essa abordagem que valoriza a perfeição técnica contém uma cilada. A boa qualidade técnica pode arruinar o caráter de documento histórico e espontâneo que os registros sonoros e imagéticos supostamente deveriam ter, ou precisariam ter, para alimentar a ilusão (ainda que consentida) do público, a respeito de estar olhando para uma janela que acessa 0 real.

Por isso, é natural que os profissionais que realizam esse tipo de filme desejem e ressaltem certo grau de imperfeição técnica na apresentação das informações sonoras. Podemos dizer que, nos filmes de found footage, a aparência de verossimilhança tem tanta importância quanto a legibilidade acústica das informações narrativas. Só dessa maneira 0 público verá alimentada sua crença (de novo, mesmo que consentida) na suposta veracidade dos sons apresentados. Mas como os sound designers que trabalham nesses filmes têm colocado essa ênfase maior na verossimilhança?
Que ferramentas estilísticas eles utilizam para isso? São essas perguntas que este ensaio procura examinar.

\section{Um modelo bem acabado}

Como estudo de caso, selecionamos para analisar uma produção da Espanha. [Rec] foi realizado em 2007, pelos diretores Paco Plaza e Jaume Balagueró, e tem sound design assinado por Oriol Tarragó. Constituiu um dos principais lançamentos dentro desse gênero da safra daquele ano, tendo garantido distribuição internacional, mesmo sendo realizado com orçamento limitado e fora dos Estados Unidos. Posteriormente, o enredo recebeu uma refilmagem estadunidense.

[Rec] é apresentado ao público como uma fita não editada, contendo imagens e sons registrados durante uma madrugada por uma equipe de televisão que realizava, na ocasião, uma reportagem sobre a rotina dos bombeiros de Barcelona durante a madrugada. Na fita, a repórter (Manuela Velasco) e o cinegrafista (Pablo) se veem trancados dentro de um prédio onde ocorre uma epidemia inesperada de um vírus, capaz de matar os infectados e revivê-los como mortos-vivos canibais e extremamente agressivos. 0 s ferimentos produzidos por esses doentes induzem a um ciclo no qual os feridos também se transformam em mortos-vivos, e assim por diante.

0 filme espanhol é objeto desta análise porque, dentre as mais de 360 falsos documentários 
codificados como found footage que foram lançados desde o sucesso de A Bruxa de Blair ${ }^{3}$ apresenta um dos modelos mais bem acabados de construção sonora. Esse modelo foi alcançado exatamente através de um equilíbrio entre legibilidade e verossimilhança que enfatiza um pouco mais a segunda, em relação ao filme de ficção tradicional, mas não abandona 0 privilégio da primeira. De fato, todas as decisões criativas tomadas pela equipe de sound design em [Rec] estão ancoradas em um conceito que pode ser resumido numa frase: verossimilhança documental reforçada, mas sem recusar a legibilidade narrativa. Entender o que se ouve ainda é tão importante quanto 0 efeito de real produzido pelos sons e imagens com aparência de documento histórico.

Antes de tudo, não nos parece coincidência que todo 0 trabalho de desenho de som que podemos ouvir em [Rec] tenha sido planejado a partir da busca por um ponto de equilíbrio entre esses dois princípios conflitantes da narrativa cinematográfica. A busca por um senso de verossimilhança reforçado que não interferisse drasticamente na legibilidade narrativa levou à formulação do conceito que guiou 0 trabalho de construção do universo sonoro de [Rec], e está ressaltado pelo sound designer do filme nos depoimentos que conseguimos reunir ao longo da pesquisa. Oriol Tarragó se referiu a este conceito numa longa entrevista concedida após 0 lançamento do filme, e também em um depoimento disponível nos extras do DVD que contém a edição especial do título, lançada num disco duplo não disponível no Brasil, mas encontrável na Espanha, em Portugal e em outros países.

0 conceito utilizado por Tarragó partiu da instrução que ouviu dos dois diretores: ele deveria tratar o som de [Rec] como se filmasse um documentário verdadeiro. 0 sound designer conta que em nos primeiros encontros com os dois diretores, antes de as gravações começarem, um dos cineastas (Paco Plaza) chegou a sugerir que todo o filme fosse todo gravado e mixado em mono (ou seja, um único canal), com os microfones fixados na câmera (2010). São os dispositivos que podem ser vistos na diegese.

\section{Após alguns testes, o sound designer preferiu descartar essa ideia e planejar, para a fase de captação do áudio em locação, uma abordagem mais convencional. Ele decidiu registrar o som direto como se trabalhasse num filme de ficção tradicional: até 10 microfones por cena, sendo}

A estatística relativa aos lançamentos cinematográficos inclui apenas longas-metragens registrados no banco de dados do IMDb. A compilação feita para esta pesquisa contém, até o momento em que este ensaio foi escrito, mais de 365 falsos documentários construídos como found footage. A lista completa e atualizada pode ser conferida em: <http://www.imdb.com/list/tagV4JrrckY/>

Microfones hipercardióides direcionais, presos em uma vara de boom e suspensos acima das cabeças dos atores, o mais próximo possível de suas cabeças, de forma a registrar com o maior volume e a menor reverberação possíveis todas as falas proferidas por eles. 
um (ou dois) microfones aéreo(s) ${ }^{4}$ para captar as vozes dos atores dentro da ambiência da locação principal (um prédio antigo em Barcelona, com pé direito altíssimo e paredes de pedra, o que dá aos sons uma assinatura acústica singular, com muita reverberação, além de rangidos do piso de madeira e ruídos provenientes da passagem da água pela encanação), e até oito microfones de lapela. A regra fundamental obedecida pela equipe de captação sonora era simples: um microfone de lapela para cada personagem com fala.

A estratégia de captação sonora utilizada, que combina o uso de microfones direcionais aéreos com uso massivo de microfones de lapela, foi tornada possível a partir da disseminação dos gravadores multipista de até oito canais, no início dos anos 2000, e atualmente é hegemônica para captar o som da locação no cinema contemporâneo (SOUZA, 2010, p. 95). Tarragó optou por utilizá-la porque ela permitia um maior grau de controle do sound designer no trabalho de "sujar" o som do filme, posteriormente, na fase de pós-produção. Em outras palavras: se optasse por gravar apenas com os microfones da câmera, como queriam os diretores, Tarragó arriscaria tornar incompreensível toda uma miríade de sons - inclusive linhas de diálogo - crucial para que 0 público pudesse entender a progressão do enredo. Ao decidir gravar todas as vozes separadamente e com a maior clareza possível, e incluir somente na pós-produção os "defeitos sonoros" que imprimiriam o senso de verossimilhança documental desejado à trilha sonora, Tarragó ganhava a possibilidade de 'sujar' o áudio do filme apenas em trechos narrativamente menos importantes. Controlada, a ilegibilidade deixava de interferir na progressão narrativa da trama.

Dessa maneira, Tarragó e a equipe de áudio passaram cerca de uma semana num estúdio de áudio, produzindo e gravando toda uma constelação de ruídos normalmente indesejáveis em produções convencionais, para acrescentar depois à trilha sonora: microfonias, pancadas no microfone, sinal saturado etc. Tarragó (2010) disse ainda que boa parte dos diálogos (não há estatísticas disponíveis) foi dublada posteriormente em estúdio, tarefa facilitada pelas características estilísticas oriundas das técnicas de registro de imagem usadas pelos diretores: planos-sequência longos - a média de duração de um plano em [Rec] é de 57 segundos, mais do que dez vezes a média das produções contemporâneas de Hollywood, que giram em torno de três a seis segundos por plano (BORDWELL, 2006 p. 122) -, com boa parte da ação física ocorrendo fora do quadro ou em áreas muito escuras da imagem. Essas escolhas, por sinal, garantem que boa parte da ação dramática de [Rec] dependa realmente do som para ser compreendida, caracterizando o que Randy Thom (1999) classificou como um "filme desenhado para 0 som".

A "sujeira" tão desejada pelo sound designer de [Rec] tem relação direta com o citado conflito entre legibilidade e verossimilhança. Para funcionar dentro da proposta do gênero found 
footage, o filme precisava ter clareza sonora, mas sem deixar de lado a aparência de registro espontâneo e não planejado. 0 público precisava interpretar as imperfeições técnicas presentes no longa-metragem como uma marca impressa pelo registro apressado, e tecnicamente inadequado, feito pelos personagens do filme - pessoas que têm suas vidas colocadas em risco diante da câmera, mas permanecem registrando os eventos extraordinários como um testemunho histórico desses eventos.

Além disso, há alguns aspectos criativos que 0 sound design de [Rec] adotou - alguns deles de forma pioneira - e que foram reutilizados depois por muitos outros filmes de found footage, entre os quais alguns dos títulos criativamente mais interessantes que se pode encontrar dentro do subgênero do horror, como o australiano The Tunnel (Carlo Ledesma, 2011), o norueguês $O$ Caçador de Trolls (Trolljegeren, André Øvredal, 2010), os americanos Filha do Mal (The Devil Inside, William Brent Bell, 2011) e Apollo 18 (Gonzalo López-Gallego, 2011), o costarriquenho O Sanatório (El Sanatorio, Miguel Angel

Gonzáles, 2011) e o estadunidense 0 Herdeiro do Diabo (Devil's Due, 2014, Matt Bettinelli-Olpin e Tyler Gillett).

A seguir, enumeramos e analisamos alguns desses aspectos criativos.
(1) 0 primeiro padrão sonoro importante é a mixagem realizada em seis canais (Dolby Digital 5.1), mas com uso mínimo e discreto dos canais surround. ${ }^{5}$ Basicamente, os canais traseiros são usados apenas para sons muito graves, de baixa frequência (como os helicópteros que surgem na metade do filme, mas que não conseguimos ver), cuja localização espacial é mais difícil de ser percebida (pois as ondas sonoras de baixa frequência viajam a velocidades menores dentro da sala de projeção). Uma exceção está no terceiro ato, que ocorre dentro de um apartamento crucial para a narrativa do filme, e que tem características especiais, servido de morada para um personagem de origem sobrenatural - e, portanto, seria desejável para o sound design que os sons e a própria textura acústica que se pode ouvir nesse local sugerisse a presença de elementos não naturais (TARSO, 2012).

Para Oriol Tarragó (2010), era importante não realizar uma mixagem convencional em seis canais, embora a tentação de fazê-lo fosse grande, pois os canais surround, como se sabe, são frequentemente utilizados pelos editores de som para evocar acusticamente ameaças à vida dos personagens que não aparecem no campo visual, usando assim o fora de quadro para acionar respostas afetivas de medo, susto e horror nos espectadores (CHION, 1994, p. 73). Tarragó sabia, contudo, que a presença constante de 
sons nos canais traseiros chamaria a atenção do público para a manipulação, nos estágios de pós-produção, da trilha sonora. Como [Rec] estava sendo apresentado como se fosse uma fita bruta, sem edição, encontrada após o desaparecimento dos moradores do prédio onde ocorre a ação vista no filme (também a equipe responsável pela gravação teria desaparecido), os indícios de uma manipulação posterior da tal fita quebrariam a suspensão da descrença, essencial para gerar 0 afeto do horror na audiência.

Essa abordagem incomum, que abre mão das infinitas possibilidades de espacialização sonora oferecidas pela tecnologia atualmente disponível, é rara no cinema comercial, mas desde o lançamento de [Rec] tem sido abraçada com vigor por grande parte dos sound designers e cineastas que trabalham com a estilística do filme de found footage, como comprova a mixagem sonora de filmes como Apollo 18, O Herdeiro do Diabo, Filha do Mal e toda a franquia Atividade Paranormal (Paranormal Activity), composta por seis títulos lançados entre 2007 e 2014. Todos esses filmes apresentam uso discreto dos canais surround, uma tendência iniciada por [Rec].

(2) 0 segundo tópico de destaque no som de [Rec] está na vasta e abundante variedade de ruídos que caracterizam e reforçam a imperfeição do registro sonoro captado na locação (microfonia, quedas do microfone, batidas, vozes sobrepostas dos atores, rangidos provenientes do manuseio do microfone, sinais saturados etc.). Esses ruídos são responsáveis diretos pela sensação que verossimilhança que preenche a trilha de áudio durante todo o filme.

Sem esses elementos de imperfeição técnica, parte crucial do efeito de real produzido pelo filme seria destruída. Por outro lado, a produção desses defeitos técnicos em estúdio permitiu, ao sound designer, controlar cuidadosamente os momentos em que as imperfeições aparecem, de forma que isso ocorre exclusivamente nos tempos mortos de "[Rec]" (ou seja, quando nada narrativamente relevante está ocorrendo) ou, no máximo, sejam defeitos que aparecem e desaparecem rapidamente, de forma a não interromper o fluxo narrativo dos diálogos, que podem ser ouvidos com clareza durante todo o longa-metragem.

Nesse ponto, [Rec] introduziu um elemento novo no som dos filmes de horror. A estratégia de espalhar boa dose de sujeita acústica ao longo de momentos narrativamente irrelevantes do longa-metragem era muito mais tímida e discreta (ou mesmo inexistente) em filmes de falso found footage anteriores, como A Bruxa de Blair e Cloverfield (Matt Reeves, 2007), e desde 0 lançamento do título espanhol tornou-se uma das assinaturas sonoras mais reconhecíveis do novo gênero filmico, como se pode ouvir em trabalhos como os longas estadunidenses $O$ Herdeiro do Diabo (Devil's Due, Matt Bettinelli-Olpin e Tyler Gillett, 2014) e Atividade Paranormal: Marcados pelo Mal (Paranormal Activity: The Marked Ones, Christopher Landon, 2014), o costarriquenho 
El Sanatorio (Miguel Alejandro Gomez, 2010) e o brasileiro Desaparecidos (David Schürmann, 2011), entre muitos outros títulos.

(3) 0 terceiro padrão sonoro destacado em $[R e c]$ é o uso extensivo de efeitos sonoros que pertencem à categoria denominada por Michel Chion (1994, p. 75) de sons objetivos internos, especialmente ruídos de respiração ofegante.

Este efeito sonoro domina praticamente de ponta a ponta todo o terceiro ato de [Rec], quando a ação dramática é tensionada ao ponto máximo, encontrando os personagens do filme em estado de alerta absoluto.

0 uso dos sons de respiração tem conexão direta com a questão do ponto de escuta. Embora este conceito tenha sido discutido e problematizado extensamente por Chion (1994, p. 89-90), a presença da câmera diegética ${ }^{6}$ (CARREIRO, 2013, p. 229) tende a reduzir a ambiguidade existente em filmes tradicionais, já que em umfound footage 0 dispositivo de registro de sons normalmente precisa ser operado ou manipulado por personagens da ficção - ou seja, o espectador sabe, a cada novo plano, em que ponto da geografia espacial da diegese encontra-se 0 aparelho que registra os sons escutados. Portanto, como o gravador de sons (seja embutido na câmera ou um dispositivo independente) deve estar sendo operado por alguém normalmente situado próximo de um microfone, é natural que o espectador possa escutar parte das reações viscerais disparadas no interior do corpo desse personagem pelos eventos extraordinários da trama.

Assim, podemos ouvir toda uma constelação de gemidos, batidas do coração e respiração ofegante. Esses ruídos - que na maior parte das ficções tradicionais seriam considerados erros técnicos ajudam a reforçar a verossimilhança dos registros sonoros, servindo também como elemento que direciona e amplia as respostas afetivas dos membros da plateia ao filme, muitas vezes gerando empatia para com os personagens da narrativa.

(4) 0 quarto padrão sonoro é também um dos mais nítidos: a ausência de música extradiegética. Desde A Bruxa de Blair, essa opção estilística vem sendo usada por diretores de falsos found footage. Porém, em anos mais recentes, muitos filmes do estilo (particularmente aqueles oriundos dos Estados Unidos e do Japão) optam pelo uso da música eletrônica drone. Esse tipo de música é construído com poucas notas, normalmente, sem uma linha melódica ou rítmica discernível, e costuma explorar fenômenos acústicos como microfonia, eco e reverberação, raramente presentes na música sinfônica de índole neorromântica, hegemônica no cinema mais tradicional. 
Essas características fazem com que muitas pessoas sequer identifiquem esses sons como musicais, alinhando-os mais com a categoria dos ruídos. Essa estratégia expressa, com nitidez, uma tendência contemporânea do sound design, que é 0 apagamento das fronteiras entre a música e os efeitos sonoros, notada por muitos pesquisadores do som cinematográfico (CARVALHO, 2009; KASSABIAN, 2003; OPOLSKI, 2013; SERGI, 1999). Produções como Noroi (Kôji Shiraishi, 2005), The Poughkeepsie Tapes (John Erick Dowdle, 2007) e 0 australiano Lake Mungo (Joel Anderson, 2008) usam esse tipo de música com economia e eficiência. [Rec] tem uma proposta mais radical: abraça com mais vigor a verossimilhança e rejeita até mesmo a música drone, preferindo esconder da audiência todos os tipos de manipulação do áudio na pós-produção. Esta tendência da recusa total de música parece ser predominante, desde $[R e c]$, em filmes de found footage fora do eixo EUA-Japão.

(5) 0 quinto padrão diz respeito à exploração generosa das texturas acústicas singulares da locação principal: a abundante reverberação do som em certos ambientes (sobretudo nos corredores do prédio) contribui para acentuar a tensão e a vastidão daquele espaço, mas sem tornar as vozes dos atores completamente ilegíveis, como ocorreria caso os editores de som do filme preferissem usar integralmente a reverberação presente na locação original, conforme gravada pelos técnicos de som direto com o uso dos microfones direcionais. Como destaca Tarragó (2010), a textura acústica do filme espanhol foi cuidadosamente manipulada em estúdio, para permitir o realce da verossimilhança, mas sem perder de vista a legibilidade.

É importante destacar, aqui, o modo criativo como [Rec] lida com os três modos de escuta mais comuns, conforme descritos por Michel Chion (1994, p. 25). 0 lugar privilegiado da escuta semântica (na qual o ouvinte direciona a atenção para o conteúdo linguístico daquilo que ouve) continua preservado, já que a maior parte da progressão dramática é apresentada através das vozes dos atores, mas o sound design de [Rec] abre espaço generoso não apenas para a escuta causal (aquela em que o som identifica ou complementa a informação visual sobre 0 acontecimento ou fonte da qual ele se origina), como também para a mais rara escuta reduzida, que valoriza a própria textura sonora ou acústica do som.

(6) 0 sexto padrão sonoro de destaque é a limpidez na apresentação das vozes dos atores. Ao mesmo tempo em que há bastante sujeira nos sons diegéticos, há também clareza nas vozes dos atores, o que permite que o princípio da legibilidade continue operando, mesmo como o reforço dos padrões que privilegiam a verossimilhança. Nesse ponto, [Rec] reformula e atualiza a estratégia estabelecida por diretores veteranos dos anos 1930, como Frank Capra e Howard Hawks (SCHICKEL, 1973), que orientavam os atores a usar diálogos sobrepostos, mas apenas em pontos específicos do roteiro em que nenhuma ação narrativa 
relevante para a trama acontecia. Dessa forma, o espectador é capaz de reter a impressão de verossimilhança documental sem ser privado de nenhuma informação importante para a compreensão da trama.

Para poder alcançar esse efeito de real sem perder a clareza, foi fundamental a estratégia de captação de vozes que registrava os planos em até 10 canais separados. Só assim era possível ter o controle total do ritmo das falas dos personagens, algo que podia ser alterado na fase de montagem sonora. Além disso, a estratégia também permitiu inserir falsos ruídos oriundos de defeitos de captação em meio a diálogos, mas apenas nos momentos em que a relevância narrativa daquilo que estava sendo dito era pequena.

(7) 0 sétimo tópico de destaque replica e atualiza uma tradição antiga do sound design dos filmes de horror. Nos sons guturais emitidos pelos zumbis, [Rec] segue a tendência dos filmes de horror, mixando as vozes reais dos atores que interpretam os monstros com urros de animais variados - leões, elefantes, tigres e cabras tratados eletronicamente, de modo a acentuar as frequências mais graves (abaixo de $300 \mathrm{~Hz}$ ) e também as mais agudas (acima de $8.000 \mathrm{~Hz}$ ). Essas frequências situadas próximas dos extremos da escola sonora são mais raras na voz humana e costumam estar presentes em animais de grande porte, 0 que acentua 0 sentido de tensão e alerta dos personagens que ouvem essas vozes (e também dos espectadores).
0 medo de animais de grande porte é um medo ancestral do ser humano, de modo que cognitivamente tendemos a compreender intuitivamente a proximidade de seres que emitem ruídos desse tipo como uma ameaça à integridade física aos personagens, algo necessário para produzir medo e repulsa - afetos fundamentais para garantir o pertencimento do filme ao gênero horror.

(8) 0 oitavo e último padrão sonoro importante do filme está no uso abundante de sons fora de quadro para injetar tensão e ameaça às cenas. Essa técnica é muito comum em filmes de horror, desde os primórdios do gênero, ainda nos anos 1930, quando o afeto do horror - a soma de medo e repulsa, de acordo com Noël Carroll (1999, p. 30) - começou a ser provocado ou realçado com a estratégia estilística de manter a origem da ameaça aos personagens humanos fora do campo de visão, caracterizando-a através de sons (música, no princípio) e usando a incerteza sobre a localização espacial dessa ameaça para estimular a sensação de horror que dá nome ao gênero fílmico.

Em filmes de found footage, nos quais a câmera adota em todo tempo a perspectiva visual de um personagem da cena, o uso de sons fora de quadro ganha ainda mais importância - e o uso intenso desse recurso em [Rec] comprova com sucesso essa tese. No longa-metragem espanhol, de fato, a própria locação do prédio antigo em Barcelona, repleta de corredores estreitos e cortada por 
uma escada em espiral onde parte das cenas é localizada, favorece um estilo de encenação que David Bordwell (2009, p. 219) chamou de "recessiva", com atores e objetos cenográficos dispostos a diferentes distâncias da câmera, criando um eixo de ação física diagonal ou perpendicular à posição da câmera.

Esse tipo de encenação favorece 0 uso de sons fora de quadro, pois elimina do campo visual parte dos elementos que fazem parte da ação - e os sons produzidos por esses elementos, que incluem zumbis, bombeiros e policiais, são ainda mais amedrontadores devido ao fato de que os espectadores, privados da oportunidade de visualizar a relação espacial entre as criaturas fora do quadro e os elementos que podem ser vistos, não conseguem perceber com exatidão qual o tamanho da ameaça oferecida pelo fora de quadro. Isso gera tensão e, em consequência, medo na plateia.

Além desses oito tópicos, é importante mencionar também a inclusão de duas cenas em que personagens do filme (repórter de televisão e cinegrafista) ensinam a outros personagens (bombeiros) a instalar corretamente microfones de lapela. A cena dá maior credibilidade à qualidade sonora positiva apresentada pelo filme, pois o espectador sabe que, na maior parte das cenas, existem pelo menos cinco microfones dentro da diegese em funcionamento (o microfone embutido na câmera, o microfone na mão da repórter e três microfones de lapela, sendo dois instalados em bombeiros e um terceiro colocado na camisa da própria repórter de TV).

\section{Conclusão}

Graças às características sonoras enumeradas nos parágrafos anteriores, acreditamos que [Rec] consiste num exemplo eficiente de como alcançar o equilíbrio delicado e necessário entre os princípios sonoros da legibilidade e da verossimilhança, garantindo que os sons simulem verdadeiros registros históricos do real sem que percam a capacidade de transmitir informações narrativas de modo contínuo e claro aos espectadores.

De modo geral, nos parece evidente que o sound design de [Rec] se tornou, desde 2007, um paradigma para filmes de found footage. Isso pode ser constatado quando examinamos de forma ampla e panorâmica a construção sonora de títulos construídos dessa forma, desde 1999 (ano do lançamento de A Bruxa de Blair) até hoje. De modo geral, até meados da década de 2000, os filmes do subgênero tinham estratégias de construção sonora bastante variáveis, distintas entre si. 0 sound design podia pender para uma legibilidade mais próxima do som de filmes de ficção tradicionais - Cloverfield (Matt Reeves, 2008), por exemplo, abusa dos efeitos em surround, embora tenha toda a ação supostamente captada por um único microfone instalado em uma câmera amadora. Em outros casos, buscava-se uma verossimilhança sonora 
extremamente fiel às limitações de captação do equipamento utilizado pelos personagens da ficção, estratégia que pode prejudicar a compreensão de fatos narrativos dentro do enredo. Isso ocorre, por exemplo, em A Bruxa de Blair, em cenas noturnas que mostram personagens reagindo de forma brusca a sons mixados em baixíssimo volume e sem espacialidade definida, de forma que o público tem dificuldade em compreender quais são esses sons e de onde vêm, sem conseguir interpretar como uma ameaça condizente com a intensidade da reação apresentada pelos personagens que reagem aos ruídos.

A partir de 2007, contudo, as estratégias de concepção sonora dos filmes de found footage passaram a convergir em direção à estética ouvida em [Rec], e que procuramos sintetizar nos oito tópicos apresentados ao longo do ensaio: uso discreto dos canais surround, música apenas diegética (ou drone), valorização do erro técnico (microfonia, sinal saturado, ruído indesejado), sons de respiração ofegante, vozes semanticamente compreensíveis, generoso uso do reverb e dos sons fora do quadro.

De modo geral, pode-se afirmar que o maior acerto de [Rec] parece decorrer da decisão criativa de registrar cada elemento sonoro presente na mixagem final (vozes, ruídos, efeitos sonoros, ambientes) separadamente, de forma limpa e clara. Essa estratégia permitiu que o sound designer tratasse 0 filme extensivamente, na pós- produção, a fim de aproximar sua estética daquela encontrada num documentário real, ampliando a importância da verossimilhança sonora sem abandonar a (ou abrir mão da) legibilidade. Dessa forma, o filme espanhol conseguiu atingir um ponto de equilíbrio que acabou por se tornar referência dentro do gênero do falso found footage, algo que pode ser confirmado quando se vê - e ouve - os filmes mais recentes que empregam esse estilo de filmagem, e apresentam clara influência do trabalho que ouvimos em [Rec].

\section{Referências}

ALTMAN, R. Sound theory, sound practice. New York: Routledge, 1992.

BARTHES, R. 0 rumor da língua. São Paulo: Martins Fontes, 1972.

BRAGANÇA, K. N. A credibilidade sobrenatural: Análise das estratégias de persuasão e do efeito de real no gênero de horror em Atividade Paranormal. In: LEITE, L. et al. (Org.). Leitor, leitora: literatura, recepção, gênero. Vitória: EDUFES, 2011. v. 1, p. 204-210.

CHION, M. Audiovision. New York: Columbia University Press, 1994.

BORDWELL, D. Figuras traçadas na luz. Campinas, SP: Papirus, 2009.

BORDWELL, D. The way Hollywood tells it: story and style in modern movies. Los Angeles: University of California Press, 2006.

BORDWELL, D. Return to Paranormalcy. 2012. Disponível em: < http://www.davidbordwell.net/ blog/2012/11/13/return-to-paranormalcy/> . Acesso em: 08 fev. 2013.

CÁNEPA, L. L.; FERRARAZ, R. Fantasmagorias das imagens cotidianas: 0 estranho e a emulação do 
registro videográfico doméstico no cinema de horror contemporâneo. In: BRASIL, A.; MORETTIN, E.; LISSOVSKY, M. (Org.). Visualidades hoje. Salvador: Edufba, 2013. p. 79-99.

CARREIRO, R. A câmera diegética: legibilidade narrativa e verossimilhança documental em falsos found footage de horror. Significação, São Paulo, v. 40, n. 40, p. 224-244, 2013.

CARREIR0, R. Sobre o som no cinema de horror. Ciberlegenda, Niterói, v. 24, n. 1, p. 43-53, 2011.

CARROLL, N. A filosofia do horror ou paradoxos do coração. Campinas, SP: Papirus, 1999.

CARVALHO, M. Anos 1970: 0 desenlace da polifonia tropical e a marginália na música de cinema”. In: LUNA, Rafael (Org.). Nas trilhas do cinema brasileiro. Rio de Janeiro: Tela Brasilis Edições, 2009. v. 1, p. 84-95.

GRANT, B. K. Digital ansiety and the new verité horror and sf film. Science Fiction Film and Television, v. 6 , n. 2, p. 153-175, 2013.

HAWKS, H. Entrevista. In: THE MAN that Made the Movies: Howard Hawks. Diretor e roteirista: Richard Schickel. Produtores: Tom Brown, Douglas Freeman, Richard Schickel. Com Howard Hawks, Sidney Pollack, Lauren Baccall, Humphrey Bogart. New York: Turner Classic Movies (TCM), 1973. Negativo em 35mm, 57 minutos. Sistema de reprodução: NTSC. Colorido. Mono.

HELLER-NICHOLAS, A. Pre-History of 'Reality' Horror Film. 013Media, Roma, v. 4, n. 9, p. 26-30, jan. 2011.

INGLE, Z. G. A. Romero's Diary of the Dead and the rise of the diegetic camera in recent horror films. 013Media, Roma, v. 4, n. 9, p. 26-30, jan. 2011.

KASSABIAN, A. The Sound of a New Film Form. In: INGLIS, Ian. Popular music and film. London: Wallflower Press, 2003. p. 91-101.

NICHOLS, B. Introdução ao documentário.

Campinas, SP: Papirus, 2005.
OPOLSKI, D. Introdução ao desenho de som: uma sistematização aplicada na análise do longa-metragem Ensaio sobre a cegueira. João Pessoa: Editora da UFPB, 2013.

RUOFF, J. K. Conventions of sound in documentary. In: ALTMAN, Rick (Org.). Sound theory, sound practice. New York: Routledge, 1992. p. 217-234.

SERGI, G. In Defence of vulgarity: The place of sound effects in the cinema. Scope: An Online Journal of Film Studies, Nottingham (UK), n. 5, 1999. Disponível em: $<$ http://filmsound.org/articles/sergi/sound-effectsplace.htm >. Acesso em: 4 fev. 2014.

SOUZA, J. B. G. Procedimentos de trabalho na captação de som direto nos longas-metragens brasileiros Contra todos e Antônia: a técnica e o espaço criativo. Tese (Doutorado em Ciências da Comunicação) Universidade de São Paulo, São Paulo, 2010.

TARRAGÓ, 0. Exclusive interview with Oriol Tarragó, Sound Designer of "Rec" and "Rec 2". 2010. Disponível em: < http://designingsound.org/2010/04/ exclusive-interview-with-oriol-tarrago-sound-designerof-rec-and-rec-2/>. Acesso em: 4 fev. 2014.

TARSO, P. de. Sonidos de terror. 2012. Disponível em: $<$ http://www.cinemaemcena.com.br/plus/modulos/lista $\mathrm{s} / ? \mathrm{tac}=$ colunas $\&$ cid $=23 \& \mathrm{pid}=42987>$. Acesso em: 4 fev. 2014.

THOM, R. Designing a movie for sound. Iris, Iowa (EUA), n. 27, p. 9-20, nov. 1999. 
Studied imperfection: [Rec] as a paradigm of sound design in found footage horror films

\section{Abstract}

Fake documentaries in found footage style have been consolidated as one of the most prolific subgenres of horror cinema. In the area of sound design, this subgenre pushes the creative boundaries toward an aesthetic that emphasizes a certain degree of technical imperfection. We intend here to analyze the sound design of /Rec] (2007), a Spanish movie directed by Paco Plaza and Jaume Balagueró, with the objective of understand how the sonic structure of the film figures out the balance between legibility and verisimilitude.

\section{Keywords}

Horror film. Sound studies. Sound design. Found footage. Zombie.
Imperfección calculada: $[R e c]$ como paradigma de diseño de sonido en el falso documental de terror

\section{Resumen}

Falsos documentales codificados como found footage se han consolidado como un subgénero prolífico del cine de terror. En el ámbito del diseño de sonido, este estilo de película empuja los límites creativos hacia una estética que valore cierto grado de imperfección técnica. Como caso de estudio, el presente trabajo tiene como objetivo analizar el diseño de sonido de [Rec] (2007), largometraje español de Paco Plaza y Jaume Balagueró, a fin de examinar cómo la película aborda el equilibrio entre la legibilidad y la probabilidad.

\section{Palabras-Clave}

Película de terror. Los estudios de sonido. Diseño de sonido. Found footage. Zombie. 


\section{Expediente}

A revista E-Compós é a publicação científica em formato eletrônico da Associação Nacional dos Programas de Pós-Graduação em Comunicação (Compós). Lançada em 2004, tem como principal finalidade difundir a produção acadêmica de pesquisadores da área de Comunicação, inseridos em instituições do Brasil e do exterior.

\section{E-COMPÓS I www.e-compos.org.br I E-ISSN 1808-2599}

Revista da Associação Nacional dos Programas

de Pós-Graduação em Comunicacão.

Brasília, v.17, n.2, mai./ago. 2014.

A identificação das edições, a partir de 2008

passa a ser volume anual com três números.

\section{CONSELHO EDITORIAL}

Afonso Albuquerque, Universidade Federal Fluminense, Brasil Alberto Carlos Augusto Klein, Universidade Estadual de Londrina, Brasil Alex Fernando Teixeira Primo, Universidade Federal do Rio Grande do Sul, Brasil Rio Grande do Sul, Brasi

Ana Gruszynski, Universidade Federal do Rio Grande do Sul, Brasil Ana Silvia Lopes Davi Médola, Universidade Estadual Paulista, Brasil André Luiz Martins Lemos, Universidade Federal da Bahia, Brasi Ângela Freire Prysthon, Universidade Federal de Pernambuco, Brasil Antônio Fausto Neto, Universidade do Vale do Rio dos Sinos, Brasil Antonio Carlos Hohlfeldt, Pontifícia Universidade Católica do Rio Grande do Sul, Brasil Antonio Roberto Chiachiri Filho, Faculdade Cásper Líbero, Brasi Arlindo Ribeiro Machado, Universidade de São Paulo, Brasil Arthur Autran Franco de Sá Neto, Universidade Federal de São Carlos, Brasil Benjamim Picado, Universidade Federal Fluminense, Brasil César Geraldo Guimarães, Universidade Federal de Minas Gerais, Brasil Cristiane Freitas Gutfreind, Pontifícia Universidade Católica do Rio Grande do Sul, Brasil Denilson Lopes, Universidade Federal do Rio de Janeiro, Brasil Denize Correa Araujo, Universidade Tuiuti do Paraná, Brasi Edilson Cazeloto, Universidade Paulista , Brasil

Eduardo Vicente, Universidade de São Paulo, Brasil Eneus Trindade, Universidade de São Paulo, Brasil Erick Felinto de Oliveira, Universidade do Estado do Rio de Janeiro, Brasi Florence Dravet, Universidade Católica de Brasília, Brasil Gelson Santana, Universidade Anhembi/Morumbi, Brasi Gilson Vieira Monteiro, Universidade Federal do Amazonas, Brasil Gislene da Silva, Universidade Federal de Santa Catarina, Brasil Guillermo Orozco Gómez, Universidad de Guadalajara Gustavo Daudt Fischer, Universidade do Vale do Rio dos Sinos, Brasil Hector Ospina, Universidad de Manizales, Colômbia Herom Vargas, Universidade Municipal de São Caetano do Sul, Brasil Ieda Tucherman, Universidade Federal do Rio de Janeiro, Brasil Inês Vitorino, Universidade Federal do Ceará, Brasil Janice Caiafa, Universidade Federal do Rio de Janeiro, Brasil Jay David Bolter, Georgia Institute of Technology Jeder Silveira Janotti Junior, Universidade Federal de Pernambuco, Brasi João Freire Filho, Universidade Federal do Rio de Janeiro, Brasil John DH Downing, University of Texas at Austin, Estados Unidos Ana Carolina Damboriarena Escosteguy, Pontifícia Universidade Católica do

José Afonso da Silva Junior, Universidade Federal de Pernambuco, Brasil José Carlos Rodrigues, Pontifícia Universidade Católica do Rio de Janeiro, Brasil José Luiz Aidar Prado, Pontifícia Universidade Católica de São Paulo, Brasil José Luiz Warren Jardim Gomes Braga, Universidade do Vale do Rio dos Sinos, Brasil Juremir Machado da Silva, Pontifícia Universidade Católica do Rio Grande do Sul, Brasil Laan Mendes Barros, Universidade Metodista de São Paulo, Brasil Lance Strate, Fordham University, USA, Estados Unidos Lorraine Leu, University of Bristol, Grã-Bretanha Lucia Leão, Pontifícia Universidade Católica de São Paulo, Brasil Luciana Panke, Universidade Federal do Paraná, Brasil Luiz Claudio Martino, Universidade de Brasília, Brasil Malena Segura Contrera, Universidade Paulista, Brasil Márcio de Vasconcellos Serelle, Pontifícia Universidade Católica de Minas Gerais, Brasil Maria Aparecida Baccega, Universidade de São Paulo e Escola Superior de Propaganda e Marketing, Brasil Maria das Graças Pinto Coelho, Universidade Federal do Rio Grande do Norte, Brasil Maria Immacolata Vassallo de Lopes, Universidade de São Paulo, Brasil Maria Luiza Martins de Mendonça, Universidade Federal de Goiás, Brasil Mauro de Souza Ventura, Universidade Estadual Paulista, Brasil Mauro Pereira Porto, Tulane University, Estados Unidos Nilda Aparecida Jacks, Universidade Federal do Rio Grande do Sul, Brasil Paulo Roberto Gibaldi Vaz, Universidade Federal do Rio de Janeiro, Brasil Potiguara Mendes Silveira Jr, Universidade Federal de Juiz de Fora, Brasil Renato Cordeiro Gomes, Pontifícia Universidade Católica do Rio de Janeiro, Brasil Robert K Logan, University of Toronto, Canadá

Ronaldo George Helal, Universidade do Estado do Rio de Janeiro, Brasil Rosana de Lima Soares, Universidade de São Paulo, Brasi Rose Melo Rocha, Escola Superior de Propaganda e Marketing, Brasil Rossana Reguillo, Instituto de Estudos Superiores do Ocidente, Mexico Rousiley Celi Moreira Maia, Universidade Federal de Minas Gerais, Brasi Sebastião Carlos de Morais Squirra, Universidade Metodista de São Paulo, Brasil Sebastião Guilherme Albano da Costa, Universidade Federal do Rio Grande do Norte, Brasil

Simone Maria Andrade Pereira de Sá, Universidade Federal Fluminense, Brasi Tiago Quiroga Fausto Neto, Universidade de Brasília, Brasil Suzete Venturelli, Universidade de Brasília, Brasil Valerio Fuenzalida Fernández, Puc-Chile, Chile Veneza Mayora Ronsini, Universidade Federal de Santa Maria, Brasil Vera Regina Veiga França, Universidade Federal de Minas Gerais, Brasil

\section{COMISSÃO EDITORIAL}

Cristiane Freitas Gutfreind I Pontifícia Universidade Católica do Rio Grande do Sul, Brasil Irene Machado I Universidade de São Paulo, Brasil

Jorge Cardoso Filho I Universidade Federal do Reconcavo da Bahia, Brasil / Universidade Federal da Bahia, Brasil

CONSULTORES AD HOC

Adriana Amaral, Universidade do Vale do Rio dos Sinos, Brasil

Alexandre Rocha da Silva, Universidade Federal do Rio Grande do Sul, Brasi Arthur Ituassu, Pontifícia Universidade Católica do Rio de Janeiro, Brasil Bruno Souza Leal, Universidade Federal de Minas Gerais, Brasil Elizabeth Bastos Duarte, Universidade Federal de Santa Maria, Brasil Francisco Paulo Jamil Marques, Universidade Federal do Ceará, Brasi Maurício Lissovsky, Universidade Federal do Rio de Janeiro, Brasil Suzana Kilpp, Universidade do Vale do Rio dos Sinos, Brasil Vander Casaqui, Escola Superior de Propaganda e Marketing, Brasil

EDIÇÃO DE TEXTO E RESUMOS I Susane Barros SECRETÁRIA EXECUTIVA I Helena Stigger EDITORAÇÃo ELETRÔNICA I Roka Estúdio
COMPÓS I www.compos.org.br

Associação Nacional dos Programas de Pós-Graduação em Comunicação

Presidente

Eduardo Morettin

Universidade de São Paulo, Brasil

eduardomorettin@usp.br

Vice-presidente

Inês Vitorino

Universidade Federal do Ceará, Brasil

ines@ufc.br

Secretária-Geral

Gislene da Silva

Universidade Federal de Santa Catarina, Brasil

gislenedasilva@gmail.com 